\title{
The effects of sodium amobarbital on odor-based responding in rats*
}

\author{
GEORGE S. HOWARD and JAMES H. McHOSE $\dagger$ \\ Southern Ilinois University at Carbondale, Carbondale, Illinois 62901
}

\begin{abstract}
Twenty-four donor rats and 24 experimental rats received 64 trials in a straight runway, on a double-alternation cycle of reward and nonreward. The drug state of the donor Ss and the relationship of the reinforcement cycle for donor Ss to that for experimental Ss were factorially manipulated. Only the experimental Ss for which the donor and experimental $\mathbf{S}$ reinforcement cycles were correlated developed patterned responding, and then only when donor Ss were undrugged. The results were interpreted as supportive of the notion that the basis for odor-based patterning is an emotional response to frustrative nonreward.
\end{abstract}

Several previous studies have shown that the reinforcement event experienced by one rat can affect the performance of the immediately following $S$ in the running order. Thus, when Ss are administered trials in running squads, with each $S$ receiving its first daily trial before any $S$ within the squad receives its second trial, the reward $(\mathrm{R})$ or nonreward $(\mathrm{N})$ event administered to one $\mathrm{S}$ may serve as a discriminative stimulus for the next $S$ in the running order (Ludvigson \& Sytsma, 1967; McHose, 1967). The observation that $\mathrm{R}$ or $\mathrm{N}$ events delivered to the first two Ss in the running order can provide discriminative stimuli for the second $\mathrm{S}$ is apparently attributable to differential odor trails left by the first $\mathrm{S}$ on $\mathrm{R}$, as compared with $\mathrm{N}$ trials (cf. Seago, Ludvigson, \& Remley, 1968).

Recent evidence suggests that previous demonstrations of odor-based responding are attributable to the fact that Ss exude distinctive odors on $\mathrm{N}$ trials only (Morrison \& Ludvigson, 1970). This observation, together with the finding that the N-trial odor trails are aversive (Collerain \& Ludvigson, 1972), suggests that these odors may be associated with an emotional response to frustrative nonreward (cf. Collerain \& Ludvigson, 1972). Within this framework, any procedure which would preclude an emotional response to frustrative nonreward by one $S$, would also eliminate odor based responding in a subsequent $S$ in the running order. The injection of sodium amobarbital is presumably such a procedure (Gray, 1969; Ison \& Rosen, 1967). The present study, then, was designed to determine whether the injection of sodium amytal to Ss which would normally provide odor-based discriminative stimuli to undrugged $S s$ would affect odor-based responding in the undrugged Ss.

*This experiment is based on a thesis submitted to the Graduate School, Southern Illinois University at Carbondale, in partial fulfillment of the MA degree requirements by the first author under the direction of the second author. The research was supported by Research Grant NSF GS 30510 from the National Science Foundation.

tRequests for reprints should be sent to James $\mathrm{H}$. McHose, Department of Psychology, Southern Illinois University at Carbondale, Carbondale, Illinois 62901.

\section{METHOD}

\section{Subjects}

The Ss were 48 experimentally naive male albino rats, 100 days old, obtained from the Holtzman Company, Madison, Wisconsin.

\section{Apparatus}

The apparatus was a black runway composed of a 10-in.-long startbox, a 20 -in. run section, and a 10 -in. goalbox. The width and height were $3.5 \mathrm{in}$. throughout. A solenoid-operated, side exit door separated the start from the run section, and a manually operated guillotine door, normally open, separated the run from the goal section. Photocell-clock circuitry provided traversal times over three successive 12-in. segments of the apparatus.

\section{Procedure}

Ten days prior to the first experimental day (Day 11), all Ss were placed on a 23-h food deprivation regimen maintained throughout the experiment. On Days 4-10, each S was handled for approximately $3 \mathrm{~min}$, prefed approximately $2045-\mathrm{mg}$ Noyes pellets (identical to the subsequent reinforcement pellets), and allowed to explore the apparatus with the goalbox unbaited.

The Ss were randomly subdivided into two basic groups with 24 Ss serving as (odor trail) donors and $24 \mathrm{Ss}$ serving as experimental Ss. All Ss were administered trials in donor-experimental couplets which remained the same throughout the experiment. Within each couplet, a trial was first administered to a donor $S$ and then to an experimental $S$ before the donor $S$ received its second daily trial, etc. Each couplet completed five trials per day, with an intertrial interval of approximately $1 \mathrm{~min}$, before the next couplet received their trials. The apparatus was swabbed with water between couplets.

With the couplet procedure in mind, the design may be viewed as a 2 by 2 factorial, with the first factor being the drug state of the donor $\mathrm{S}$ within a couplet. Half of the donor Ss received, $7 \mathrm{~min}$ prior to their first trial of each day, an injection of $20 \mathrm{mg} / \mathrm{kg}$ sodium amytal $(2 \mathrm{ml} / \mathrm{kg}$ of a $10-\mathrm{mg} / \mathrm{ml}$ solution of isotonic saline), while the remaining donor Ss received a placebo injection of isotonic saline. The second factor was the relationship of the reinforcement schedule administered to donor Ss to the schedule administered to experimental Ss. All Ss received a double alternation schedule of reward (R) and nonreward $(\mathrm{N})$. For the pattern $(\mathrm{P})$ group, the reinforcement event received by an experimental $S$ on any one trial was the same as that received by the donor on that trial, i.e., within a couplet, an $\mathrm{R}$ event for an experimental $\mathrm{S}$ was always preceded by an $\mathrm{R}$ event for the donor $\mathrm{S}$ and an $\mathrm{N}$ event was always preceded by an $\mathrm{N}$ event for the donor $\mathrm{S}$. For the nonpattern group 


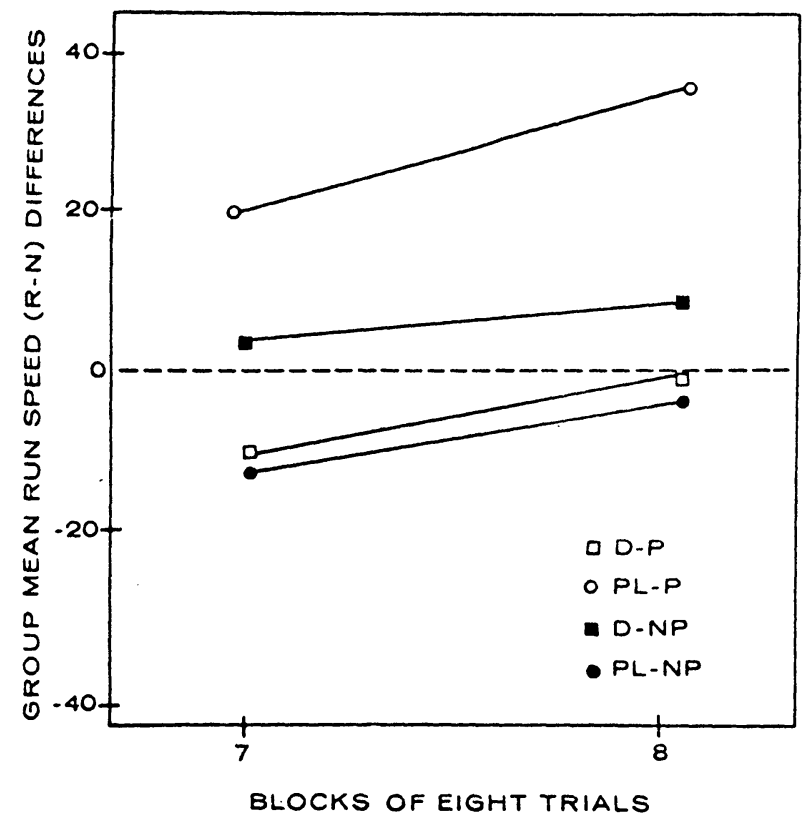

Fig. 1. Group mean speed differences (R-N) for the various groups as a function of trial blocks.

(NP), the reinforcement event received by a donor S on any trial was unrelated to the reinforcement event received by the experimental $S$ on that trial. The design then provided for four experimental groups labeled according to the drug state of the donor (D or PL), and the patterning condition: D-P, D-NP, PL-P, and PL-NP.

On Days 11 and 12 an $R$ event consisted of $20 \mathrm{sec}$ access to food pellets; beginning with Day 13, R events consisted of 16 pellets. On N trials, Ss were confined to the goalbox for $20 \mathrm{sec}$. An individual trial commenced with the placement of $S$ in the startbox. The startdoor was opened following a 3-sec orientation, and the $S$ was removed from the goal section following consumption of the reward or, on $\mathrm{N}$ trials, following confinement. All Ss received 64 such trials.

\section{RESULTS AND DISCUSSION}

Of the three recorded response measures, the second 12 in measure (the run measure) proved most statistically reliable. Before turning to the data of primary interest, that for the experimental Ss, two salient aspects of the donor $\mathrm{S}$ data should be noted. First, analysis of variance of these data over the last 16 trials (Trials 49-64) indicated that placebo injected donor Ss ran reliably faster than did donor Ss injected with sodium amobarbital $(F=63.4, \mathrm{df}=1,20, \dot{\mathrm{p}}<.01)$. Secondly, speeds on R trials did not differ reliably from speeds on $\mathrm{N}$ trials. The observation that the injection of sodium amobarbital depressed the performance of the donor Ss, Ss which received partial reward throughout training, is consistent with previous findings (Barry, Wagner, \& Miller, 1962; Wagner, 1963). For present purposes, the observed effect of the drug on donor performance merely indicates that, in this study, the drug affected the performance of partially rewarded Ss in a fashion which has elsewhere (e.g., Wagner, 1963) been interpreted as indicative of the frustration-reducing properties of the drug.

Group mean speed differences (R-N) over the last two blocks of 8 trials for experimental Ss are plotted in Fig. 1. As may be seen in Fig. 1, only Group PL-P developed substantially faster speeds on $R$ as compared with $\mathrm{N}$ trials. Analysis of variance of the data over the last 16 trials, including the drug, pattern vs nonpattern, and $\mathrm{R}$ vs $\mathrm{N}$ factors yielded a significant Pattern by Drug by $\mathrm{R}$ vs $\mathrm{N}$ interaction $(\mathrm{F}=8.96$, df $1,20, \mathrm{p}<.01)$. Subsequent pair comparisons ( $t$ tests) indicated that the R-N difference was statistically reliable $(p<.01)$ only for Group PL-P. There were no statistically reliable differences between groups on either $\mathrm{R}$ or $\mathrm{N}$ trials.

The data for experimental Ss which followed undrugged donors (Groups PL-P and PL-NP) indicates that patterning (faster R-trial speeds than $\mathrm{N}$-trial speeds) on the double alternation cycle of $\mathrm{R}$ and $\mathrm{N}$ trials developed only when the donor $\mathrm{S}$ in the running couplet received the same reinforcement event, on each trial, as did the experimental $\mathrm{S}$. In this respect, the present data are consistent with previous findings (e.g., Ludvigson \& Sytsma, 1967; Seago et al, 1968), and are supportive of the notion that donor Ss exuded differential odors on $\mathrm{R}$ as compared with $\mathrm{N}$ trials, odors which served as discriminative stimuli for Group PL-P, but not for Group PL-NP. The further observation that Group D-P did not develop patterned responding indicates, then, that the administration of sodium amobarbital to donor Ss in some fashion inhibited odor-based patterning in the experimental Ss. The present interpretation of this finding is that the administration of sodium amobarbital prevented an emotional response to frustrative nonreward by the donor Ss and, consequently, these Ss provided no odor trails which could cue impending $\mathrm{R}$ or $\mathrm{N}$ events for experimental Ss.

\section{REFERENCES}

Barry, H., Wagner, A. R., \& Miller, N. E. Effects of alcohol and amobarbital on performance inhibited by experimental extinction. Journal of Comparative \& Physiological Psychology, 1962, 55, 464-468.

Collerain, I., \& Ludvigson, H. W. Aversion of conspecific odor of frustrative nonrew ard in rats. Psy chonomic Science, 1972, 27, 54-56.

Gray, J. A. Sodium amobarbital and the effects of frustrative nonreward. Journal of Comparative \& Physiological Psychology, 1969, 69, 55-64.

Ison, J. R., \& Rosen, A. J. The effects of amobarbital sodium on differential instrumental conditioning and subsequent extinction. Psychopharmacologia, 1967, 10, 417-425.

Ludvigson, H. W., \& Sytsma, D. The sweet smell of success: Apparent double alternation in the rat. Psychonomic Science, 1967, 9, 283-284.

McHose, J. H. Patterned running as a function of the sequence of trial administration. Psychonomic Science, 1967, 9, 281-282.

Morrison, R. R., \& Ludvigson, H. W. Discrimination by rats of conspecific odors of reward and nonreward. Science, 1970, 167, 904-905.

Seago, J., Ludvigson, H. W., \& Remley, N. R. Effects of anosmia on apparent double alternation in the rat. Journal of Comparative \& Physiological Psychology, 1968, 71, 435-442.

Wagner, A. R. Sodium amytal and partially reinforced runway performance. Journal of Experimental Psychology, 1963, 55, 474-477.

(Received for publication December 14, 1973.) 